\title{
Considerações em torno de dois modelos-limites de ensino
}

* José D’Assunção Barros

\begin{abstract}
RESUMO
Propõe-se desenvolver uma argumentação em torno da oposição entre dois modelos limites de ensino - tema que se encontra em permanente debate: o ensino que se ampara na ideia de transmissão de conhecimento, e o ensino que se ampara na ideia de produção de conhecimento. 0 texto não propõe discutir bibliografia sobre o tema e seus assuntos correlatos, mas apenas apresentar algumas posições do autor no sentido de estimular o debate em torno de uma questão que está sempre em pauta na prática cotidiana do ensino.
\end{abstract} * Universidade Federal Rural

Palavras-chave: Produção de conhecimento. Transmissão de conhecimento. Modelos de ensino.

\begin{abstract}
It is proposed to develop an argumentation, in relation to a permanent debate, about the opposition between two models of Education: that based in the idea of transmission of knowledge, and that based on the notion of production of knowledge. The text does not proposes to discuss bibliography about the theme and its correlated aspects, bur only to present some positions of the author in the sense of to stimulate the debate around a question that is ever present in the quotidian practice of Education.
\end{abstract}

Keywords: Production of Knowledge. Transmission of Knowledge. Models of education

\section{CONSIDERAÇÕES EM TORNO DE DOIS MODELOS DE ENSINO}

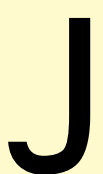

á não apresenta muita novidade, nos dias de hoje, contrapor em Congressos de Educação ou Pedagogia os antigos modelos de ensino, apoiados na ideia de 'transmissão de conhecimento', aos modelos de ensino que buscam seu suporte na noção de "produção do conhecimento". Grandes nomes da Teoria da Educação, a começar por Paulo Freire (1921- 
1997), são já referências obrigatórias em todos os cursos de Pedagogia ${ }^{1}$. Contudo, a constatação de que na realidade efetiva das salas de aula ainda predominam muitos aspectos de um Ensino que, em teoria, já é por muitos considerado uma página a ser revisada na História da Educação, leva-nos a olhar para o passado para apreciar aspectos presentes em um caminho percorrido ${ }^{2}$. 0 presente artigo coloca-se como texto para Debate, apresenta-se como relato de um professor, como texto opinativo que se desenvolve para estimular a troca de opiniões e, desse modo, apresenta-se em modelo ensaístico, de reflexão livre.

Começaremos por retomar a ideia e a consciência de que o século XX foi certamente o cenário de profundas mudanças no âmbito do ensino e da aprendizagem, em todos os níveis e campos de saber. Neste início de novo milênio, as mudanças são certamente bem perceptíveis no plano teórico e no âmbito das ideias. Os congressos de Pedagogia falam nelas abertamente, as teses de Mestrado e Doutorado discutem um novo modelo de ensino que teria superado o ensino tradicional. As palestras dos grandes educadores mostram-nos os sintomas mais claros de que assistimos neste último século à passagem de um ideal de ensino centrado no autoritarismo e no modelo da 'transmissão do conhecimento' para um modelo mais democrático, centrado na 'produção do conhecimento ${ }^{3}$ '. Examinemos de perto o que se propõe a ser a passagem de um modelo de ensino a outro, mas sempre tendo em vista que, nesse caso, estaremos trabalhando com a abstração de dois modelos-limite que não ocorrem necessariamente de forma dicotomizada nas experiências educacionais concretas e históricas ${ }^{4}$.

Bem sabem os historiadores que a cultura material de uma sociedade revela algo do que foi essa sociedade, algo da sua vida concreta e cotidiana, do seu imaginário, das suas relações de poder. Quando examinamos as grandes salas de aula construídas no século XIX, ou mesmo antes muitas das quais ainda são utilizadas nos dias de hoje nas universidades e instituições de ensino que herdaram patrimônios materiais anteriores podemos enxergar ali em detalhe um sistema de hierarquias e relações de poder, bem como um mundo bem definido de ideias em relação ao ensino.

O modelo mais típico é o da sala que tem na sua posição mais em
1 Entre algumas das mais importantes obras de Paulo Freire relacionadas ao campo educacional, ver: (1) Freire (1970 [1968]); Freire (1981); Freire (1985); Freire (1992); Freire (1995); Freire, (1996). Sobre o pensamento de Paulo Freire, conforme a análise de outros autores, ver: Barreto (1998); Brandão (1981); Cunha (1985); Damke, (1995); Scocuglia (1999).

${ }^{2}$ A idéia de que a Educação não se deveria restringir ao ensino do conhecimento como algo acabado e pronto, e sim como algo que deveria ser produzido, inclusive a partir da própria vivência dos alunos, já aparece em Dewey (1859-1952), na primeira metade do século XX. Desenvolvimentos mais avançados da perspectiva de um conhecimento a ser construído, e não transmitido do professor para o aluno, ocorrem com vertentes que avançam por uma crítica social da educação, tal como a da Pedagogia Libertadora, proposta por Paulo Freire, ou como as tendências progressistas libertárias, que vai encontrar seus expoentes mais significativos em nomes como Ferrer y Guardia (1849-1909), Célestin Freinet (1896-1966), Michel Lobrot, Vasquez, Oury, entre outros. Sobre a Pedagogia Libertária de Ferrer y Guardia - que culmina com a criação da 'Escola Moderna' em 1901 e com a fundação em 1907 da Liga Internacional para a Educação Racional da Infância - ver: Safón (2003). Sobre Célestin Freinet, ver: Freinet (1975). Para as ideias de Michel Lobrot, ver: Lobrot (1980, 1995). Para as propostas de Vasquez e Oury, ver: Oury (1967).

3 As tendências de ensino centradas na transmissão do conhecimento, na verdade bem vivas na prática escolar em nossos dias, podem ser indicadas pelas tendências 'Liberal Tradicional' e 'Liberal Tecnicista', esta última encontrando alguma influência das idéias behavioristas de Skinner. No Brasil, esse modelo foi reforçado pela 
evidência uma grande mesa na qual irá se sentar o professor. Diante dele estão as carteiras onde se sentarão os alunos, muitas vezes em um degrau mais baixo. 0 tablado que separa o professor do aluno na arquitetura do ensino típico do século XIX tem muito a nos dizer a respeito de um sistema de ideias para o qual ele fornece uma base material bem definida: 0 professor é o grande detentor do conhecimento que deverá ser transmitido; ele situa-se em um plano mais alto da sala, ou pelo menos em um plano em mais evidência. Mais abaixo se situa a multidão de alunos, pobres recipientes vazios de conhecimentos, que deverão ser preenchidos pelo professor com tudo aquilo que eles necessitam saber.

Nesse sistema, será função do professor transmitir a seus alunos tanto quanto possível o seu "conhecimento" - palavra que para essa época mais remota muitas vezes se confundia com informação. 0 objetivo do professor nesta arquitetura e nesse sistema de ensino é criar clones de si mesmo: quanto mais parecidos com ele próprio resultarem os alunos ao final de seu curso, mais ele terá sido bem sucedido. Em contrapartida, os alunos que resultarem pouco parecidos com o seu mestre serão considerados os que fracassaram, os recipientes vazios que não conseguiram captar o líquido de conhecimento que o mestre magnanimamente derramou sobre eles.

Esse sistema de ensino traz consigo um sistema de avaliação peculiar $^{6}$. Em um sistema que considera que a função do educador é transmitir um conhecimento que já existe previamente, e que é aquele que já traz consigo o mestre no início do processo de ensino, a avaliação não pode ser senão a da mensuração. Busca-se medir nos alunos a quantidade de conhecimento que foi neles depositada, ou melhor, o acúmulo de informação que o aluno-recipiente consegue reter. Surge aí a figura da prova - sem consulta, nem a livros nem ao colega - muitas vezes um tipo de prova que avalia informações, que exigirá respostas prontas e únicas, as mesmas respostas que daria o professor e que são consideradas as únicas corretas. A "nota" maior caberá ao recipiente que se mostrar mais cheio do mesmo líquido de saber que contém o professor, e com ela será premiado o clone, enquanto com as notas mais baixas serão punidos os alunos que, por negligência ou insubordinação, deixaram escapar o precioso saber que thes quis transmitir o seu mestre. Ou, ainda pior, que aprenderam algo que não devia - que se encheram de um líquido estranho que antes não estava previsto.
Ditadura Militar, a partir de medidas para uma reforma educacional do final dos anos 1960, embora o modelo tecnicista já estendesse sua influência nos meios educacionais brasileiros desde meados dos anos 1950.

4 Se pudermos situar no âmbito do modelo de ensino baseado na transmissão de conhecimento as tendências liberais tradicional e tecnicista, e se podemos situar a Pedagogia Libertadora de Paulo Freire e as pedagogias libertárias como modelos que se voltam para a produção do conhecimento, as tendências liberais renovadas - possíveis de serem ilustradas com as propostas de Dewey, Montessori, Decroly e Coussinet - já podem ser compreendidas como situações intermediárias, que trabalham com perspectivas encontráveis em cada um dos dois modelos-limite. Da mesma forma, na sua experiência cotidiana os professores costumam trabalhar com uma mescla possível de atitudes que podem ser relacionadas a um e a outro modelo, mesmo porque tem que se adaptar ao contexto institucional, legal e também à sociedade que os envolve e que se reflete também em um certo modelo de aluno produzido a partir do ambiente familiar e social. Para as idéias de Dewey, ver: Dewey (1979 [1916]).

6 Para uma reflexão sobre sistemas de avaliação ver: Berbel (2001); Luckesi (1994, 1986); Camargo (1996); Hoffman (1993); Sordi (2001); Haas (2003); Romanowski, (2003). 
Entre as estratégias de enfrentamento deste tipo de avaliação está aquilo que é vulgarmente chamado de "decoreba" - sistema através do qual você ocupa momentaneamente a sua memória descartável com informações que the serão exigidas no dia da prova e que posteriormente desaparecerão do seu cérebro como se nunca tivessem existido. Esse tipo de prova mensuradora requer, naturalmente, estrita vigilância e controle. 0 professor deverá fiscalizar atentamente os seus alunos para se assegurar de que eles estarão fazendo a prova em completo estado de isolamento. A sala de aula, nos dias de prova, estará completamente silenciosa - pouca diferença encontraremos entre ela é uma sala de velório que vela o seu defunto.

Diante deste modelo surge a inevitável resistência: a cola! ${ }^{7}$ A cola é a resposta do aluno a um modelo de ensino que, inconscientemente ou não, ele percebe ser extremamente autoritário. Através da cola o aluno pode consultar o livro que the é proibido no momento da prova. Ou então, consulta-se o colega ao lado - o outro recipiente que talvez tenha sido mais feliz na captação das informações que foram transmitidas pelo professor durante o curso. As tecnologias da cola multiplicam-se, e através delas talvez o aluno dos tempos antigos consiga desenvolver mais criatividade em uma única noite do que foi possível a ele desenvolver durante todo um curso. Uns tatuam na palma das mãos as informações que thes serão exigidas. Outros localizam discretamente um livro sob a mesa, talvez pronto para ser lido pela primeira vez, enquanto os alunos mais audaciosos e criativos elaboram habilmente pequenos protótipos de micro-filmes: pequenos rolinhos de papel que contém todas as informações das quais dependerá a continuidade de sua vida acadêmica. Outros, enfim, desenvolvem sistemas de comunicação a distância, por meio dos quais se comunicam com os dedos, com caretas que representam as letras das respostas das questões de múltipla escolha. A prova de múltipla escolha, aliás, encontra neste sistema de ensino um lugar especial, já que ele prevê respostas únicas em detrimento de todas as demais.

Não fosse a tecnologia marginal da cola, que estimula a comunicação entre os alunos que enfrentam a avaliação, ou que exige pelo menos um momentâneo diálogo com os livros da parte do aluno que opta pelos métodos mais solitários, poder-se-ia dizer que tal sistema de ensino educa integralmente para a auto-suficiência, para o isolamento, para a nãosociabilidade, para a competitividade.
7 Para uma reflexão sobre a Cola, ver: Martins (2008a, 2008b, 2008c); Silva, G. A; ROCHA et al. (2006); Thums (2002). 
Passemos agora ao modelo de ensino para o qual deslizaram, ao menos no plano imaginário, os novos ideais educativos. Do antigo sistema que via o professor como um transmissor do conhecimento, passa-se agora a um novo sistema que propõe para os educadores o papel de um mediador do conhecimento. Nesse novo sistema, o professor deverá descer do seu Olimpo, o tablado necessariamente se desmonta. Se no sistema anterior era-lhe recomendável distância em relação ao aluno, estranhamento, ausência de afetividade para que esta não interfira na sua função de controle e na sua prática de mensuração, agora o professor poderá ensaiar uma maior aproximação em relação ao aluno. Um mediador não deve ser um fiscal que irá medir se o conhecimento foi transmitido, mas sim um líder que deverá estimular a produção do conhecimento.

Diante desse novo padrão, a arquitetura deve mudar de pronto. Professor e aluno não deverão estar mais separados por um tablado. 0 educador-mediador e os alunos que produzirão o conhecimento, e que não mais o receberão pronto e acabado das mãos magnânimas do mestre, podem estar agora no mesmo plano. Considera-se que o aluno não é mais o recipiente vazio, mas sim um ser humano cheio de especificidades, com as quais, inclusive, deve aprender o professor. Cada aluno possui vivências que os outros não têm, e que o próprio professor também não possui. Nesse sentido, todos - alunos e professor - são agentes igualmente importantes para a construção de um conhecimento que será elaborado ali, pela primeira vez, como produto novo elaborado por um grupo de trabalho que tem as suas próprias singularidades.

Nesse novo modelo de ensino, o conhecimento jamais pode coincidir meramente com a informação. Quando muito, a informação é o material do qual se parte ou ao qual se chega, é o meio por meio do qual o conhecimento se elabora, em alguns casos um subproduto. Não mais que isso. O que importa no ensino centrado na 'produção do conhecimento' não pode ser nunca a informação, mas sim o que você fará com a informação, como você irá conectar informações dispersas para produzir algo novo, algo que não estava previsto, algo que só poderia ter sido produzido por aquele grupo, e não por outro.

Para dar um exemplo dos mais banais no ensino de História, não existe, a partir dessa perspectiva, qualquer sentido em propor uma pergunta como "Quem descobriu o Brasil" para obter como resposta "Pedro 
Álvares Cabral". Iniciar um processo de produção do conhecimento é, por exemplo, propor uma desconstrução dessa pergunta, questionar os seus limites, a ideologia que a construiu; é tentar identificar quem fez pela primeira vez esse tipo pergunta, e quem continua a fazê-la nos dias de hoje... com que finalidades, para moldar que tipo de mentes e para impor sutilmente que formas de sujeição. Produzir conhecimento a partir desse mais banal clichê do ensino de História do Brasil é propor substituições nas palavras que constituem essa pergunta: é perguntar se o Brasil foi descoberto ou foi invadido.

Esse exemplo deve ser entendido como uma metáfora para questões mais complexas. 0 mais importante é perceber, para qualquer questão imaginável, que a postura de ensino antiga, pouco sintonizada com os novos tempos, consiste em impor autoritariamente a transmissão do conhecimento, ou então - da perspectiva do aluno - aceitar passivamente essa mesma transmissão do conhecimento. Quando um aluno vai à Internet para fazer um trabalho, e copia e cola integralmente o texto que está postado em alguma página da Web, sem sequer indagar os seus limites, ele não está se envolvendo em um processo de produção de conhecimento, está meramente concordando em ser o polo passivo de uma transmissão do conhecimento. Usar a Internet para copiar e colar informação é usar uma ferramenta moderna para reproduzir uma postura antiga, é sintonizar-se com os tempos pré-jurássicos em que o professor passava o tempo inteiro de uma aula escrevendo no quadro-negro algo que queria transmitir, e os alunos copiavam passivamente.

Usar a Internet para produzir conhecimento, e não para meramente aceitar a transmissão de conhecimento, é comparar informações de origens diversas, conectá-las, problematizá-las, utilizá-las como meio para produzir um novo texto. Produzir conhecimento é fazer algo com a informação, e não simplesmente transferi-la da tela de um computador para a folha de papel impresso por meio de um processo em que praticamente não ocorreu uma maior intervenção da inteligência e da criatividade. Não é a ferramenta que precisa ser moderna; as cabeças dos alunos e professores - é que têm de ser modernas ${ }^{8}$.

Mas voltando ao polo que nos interessa neste momento, o professor, é preciso lembrar que no modelo em que o conhecimento é produzido, e não transmitido, não há como o educador prever rigorosamente o que

8 Assim, quando o professor propõe uma questão não- problematizada, não deixa de estar fazendo um convite a estes artifícios não-criativos. Se proponho uma questão como "fale sobre a Revolução Francesa”, estou convidando o aluno mais preguiçoso a copiar um texto já pronto. Mas se proponho uma questão problematizada como "compare a Revolução Francesa com a Revolução Inglesa", fecho automaticamente os caminhos da mera reprodução de informações e textos extraídos de algum lugar. 
acontecerá em um determinado curso. Se o conhecimento não aparece como um produto que já estava pronto e acabado antes de tudo começar, não há como fixar etapas rigorosas e inflexíveis, ou como exigir resultados que já haviam sido previstos de antemão, para finalmente premiar e punir conforme a aproximação ou distanciamento em relação a parâmetros previamente idealizados. Premia-se o processo, a capacidade de construir algo novo, de dar algum sentido a informações que não são mais do que materiais de passagem.

Os próprios modelos de avaliação devem ser agora revistos. Se a produção de conhecimento é em todos os tempos e na própria vida uma atividade interativa, em que os agentes e os meios se comunicam, propor uma prova para ser feita em estado de isolamento em relação aos outros e aos livros parece ser despropositado. Se o importante não é a informação que está no livro, mas sim o que será feito com a informação que está no livro, porque exigir que o aluno retenha na memória descartável, dados que logo desaparecerão de sua mente e concentrar os objetivos do processo avaliativo na mensuração desses dados? Quando é priorizado o processo de 'produção do conhecimento', pode desaparecer a necessidade de controle exercido a partir de um ponto centralizado ocupado pelo professor, e com isso desaparecem as já mencionadas formas de resistência a esse controle.

Para além dos aspectos até aqui discutidos, é preciso notar que quando se ultrapassa do modelo em que o conhecimento é transmitido linearmente do professor para cada aluno individualmente, e se atinge $o$ modelo em que o conhecimento é produzido interativamente por todos, as relações entre professor e aluno deverão se transmutar. Agora é permitida uma aproximação, a afetividade não é um entrave para os processos de controle, o distanciamento não é mais uma virtude.

De modo simplificado e esquemático, eis aqui um modelo novo de ensino que, via de regra, é enaltecido nos encontros que discutem o ensino e a aprendizagem. Ninguém quer ficar no lado da 'transmissão do conhecimento', todos pretendem ser os colaboradores de uma nova era em que o que se busca é a 'produção do conhecimento', ao lado de relações menos autoritárias. Metaforicamente falando, ninguém declara ter saudades das antigas salas de aula onde um tablado separava o professor e seus alunos. Todos estão perfeitamente adaptados à nova arquitetura do 
ensino. Mas aqui se pergunta: quantos de nós não reconstruímos o tablado imaginariamente por meio de um gesto que nos separa definitivamente do aluno, de uma ridicularização à pergunta que fez o aluno ao buscar esclarecimento para suas dúvidas, de uma maneira de falar que se quer incompreensível e que reconstrói o tablado a partir da própria língua, de um título de mestre ou doutor que é ostentado de maneira arrogante para mostrar ao aluno que ele está abaixo do professor, este detentor máximo do conhecimento?

Esse ensino antigo, das salas de aula com espaços hierarquizados, estará assim tão distante no tempo, ou convive lado a lado com as práticas e posturas mais modernas de ensino? Não estaremos vivendo em um mundo cindido, onde ao lado das propostas realmente inovadoras o antigo também se disfarça no novo por meio de novos materiais para disfarçar antigas práticas, da proliferação de esclerosadas ideias que renascem através novos discursos, de maneiras sutis de impor e perpetuar velhas hierarquias por meio de uma arquitetura de ensino aparentemente mais democrática? Essas perguntas ficam no ar.

\section{Referências}

BARRETO, Vera. Paulo Freire para educadores. São Paulo: Arte \& Ciência, 1998.

BERBEL, Neusi Aparecida Navas. Avaliação da aprendizagem no ensino superior. Londrina: UEL, 2001.

BRANDÃO, Carlos Rodrigues. O que é método Paulo Freire. São Paulo: Brasiliense, 1981.

CAMARGO, Alzira Leite Carvalhais. 0 discurso sobre a avaliação escolar do ponto de vista do aluno. 1996. $302 \mathrm{f}$. Tese (Doutorado) Universidade Estadual de Campinas. Faculdade de Educação, Campinas, 1996.

CUNHA, Diana A. As utopias na educação: ensaios sobre as propostas de Paulo Freire. Rio de Janeiro: Paz e Terra, 1985.

DAMKE, Ilda Righi. 0 processo do conhecimento na pedagogia da libertação: as ideias de Freire, Fiori e Dussel. Petrópolis: Vozes, 1995.

DEWEY, John. Democracia e educação. São Paulo: Nacional, 1979. 
[original: 1916].

FREINET, Célestin. As técnicas Freinet da escola moderna. Lisboa: Estampa, 1975.

FREIRE, Paulo. Ideologia e educação: reflexões sobre a não neutralidade da educação. Rio de Janeiro: Paz e Terra, 1981.

FREIRE, Paulo. Pedagogia da autonomia. Rio de Janeiro: Paz e Terra, 1996.

FREIRE, Paulo. Pedagogia da esperança: um reencontro com a pedagogia do oprimido. Rio de Janeiro: Paz e Terra, 1992.

FREIRE, Paulo. Pedagogia do oprimido. Rio de Janeiro: Paz e Terra, 1970. (New York: Herder \& Herder, 1970) [manuscrito original em português: 1968].

FREIRE, Paulo. Pedagogia: diálogo e conflito. São Paulo: Editora Cortez, 1995.

FREIRE, Paulo. Por uma pedagogia da pergunta. Rio de Janeiro: Paz e Terra, 1985.

HAAS, Célia.M. Reflexões interdisciplinares sobre avaliação da aprendizagem. In: MENESES, João Glauberto de Carvalho; BATISTA, Sylvia Helena Souza da Silva. (Org.). Revisitando a prática docente interdisciplinaridade, políticas públicas e formação. São Paulo: Pioneira Thomson Learning, 2003.

HOFFMAN, Jussara. Avaliação mediadora: uma prática em construção da pré-escola à universidade. Porto Alegre: Editora Mediação, 1993.

LOBROT, Michel. Pedagogia institucional: la escuela hacia la autogestión. Buenos Aires: Humanitas, 1980.

LOBROT, Michel. Para que serve a escola? Lisboa: Terramar, 1995.

LUCKESI, Cipriano Carlos. Avaliação da aprendizagem escolar. São Paulo: Cortez, 1994.

LUCKESI, Cipriano Carlos. Avaliação educacional escolar: para além do autoritarismo. Revista de Educação AEC. Brasília, v. 15, n. 60, p.23-37, abr./jul., 1986.

CAMARGO, Alzira Leite Carvalhais. 0 discurso sobre a avaliação escolar do ponto de vista do aluno. 1996. $302 \mathrm{f}$. Tese (Doutorado) Universidade Estadual de Campinas. Faculdade de Educação, Campinas, 1996.

MARTINS, Vicente. Para uma postulação do direito de colar. [S. l.]: K-Plus, 2008a. 
Disponível em: <http://kplus.cosmo.com.br/materia. asp?co=269\&rv=Literatura>. Acesso em: 30 jun. 2015.

MARTINS, Vicente. Como a escola deve encarar a cola. [S. l.]: Usina de Letras, 2008b.

Disponível em:<http: / /www.usinadaspalavras.com/ler.php?txt_ id=64828>. Acesso em: 30 jun. 2015.

MARTINS, Vicente. A cola como direito do aluno de aprender como quer. Espaço Acadêmico, n. 37, jun. 2008c. Disponível em: <http://www. espacoacademico.com.br/037/37pc_martins.htm>. Acesso em: 30 jun. 2015

OURY, Fernand; VASQUEZ Aida. Vers une pédgogie institutionnelle. Vigneux: Maspero, 1967.

ROMANOWSKI, Joana Paulin; WACHOWICZ, Lílian Anna. Avaliação formativa no ensino superior: que resistências manifestam os professores e os alunos. In: ANASTASIOU, Lea das Graças Camargos; ALVES, Leonir Pessate (Org.). Processos de ensinagem na universidade: pressupostos para as estratégias de trabalho em aula. Joinville, SC: UNIVILLE, 2003.

SAFÓN, Ramón. O racionalismo combatente de Francisco Ferrer y Guardia. São Paulo: Imaginário, 2003.

SILVA, Gabriela Andrade da et al. Um estudo sobre a prática da cola entre universitários. Psicologia, Reflexão e Crítica, v. 19, n. 1, p. 1824, 2006.

SCOCUGLIA, Afonso Celso. A história das ideias de Paulo Freire e a atual crise de paradigmas. João Pessoa: Editora Universitária, 1999.

SORDI, Mara Regina Lemes de. Alternativas propositivas no campo da avaliação: por quê não? In: CASTANHO, Sérgio; CASTANHO, Maria Eugênia L.M. (Org.). Temas e textos em metodologia do ensino superior. Campinas: Papirus, 2001.

THUMS, Jorge. Cola online e ética no conhecimento. Salamanca/ Espanha: Ulbra, 2002. 